\title{
HUBUNGAN ANTARA MOTIVASI PERAWAT DAN SUPERVISI DENGAN KUALITAS PENDOKUMENTASIAN PROSES KEPERAWATAN
}

\section{Tati Oktiana Tamba}

\author{
Tatitamba26@gmail.com
}

\section{LATAR BELAKANG}

Proses keperawatan merupakan metode ilmiah yang dipakai dalam memberikan asuhan keperawatan yang profesional. Perawat, dimana saja ia bertugas, menghadapi klien dengan segala macam kasus, dan melayani klien pada semua tingkat usia juga harus menggunakan proses keperawatan. Perawat diharapkan memahami tentang konsep proses keperawatan dan mampu menerapkan serta menyusunannya dalam sebuah dokumen status kesehatan klien (Rohmah, N dan Walid, S. 2009).Mutu asuhan keperawatan dapat tergambar dari dokumentasi proses keperawatan (Gillies, 1994).

Dokumentasi dalam keperawatan memegang peranan penting terhadap segala macam tuntutan masyarakat yang semakin kritis dan mempengaruhi kesadaran masyarakat akan hak-haknya dari suatu unit kesehatan. Pendokumentasian merupakan suatu kegiatan pencatatan, pelaporan atau merekam suatu kejadian serta aktivitas yang dilakukan dalam bentuk pemberian pelayanan yang dianggap penting dan berharga (Dalami, 2011). Pendokumentasian yang tidak dilakukan dengan lengkap dapat menurunkan mutu pelayanan keperawatan karena tidak dapat mengidentifikasi sejauh mana tingkat keberhasilan asuhan keperawatan yang telah diberikan, dalam aspek legal perawat tidak mempunyai bukti.

Dokumentasi asuhan keperawatan menggunakan pendekatan proses keperawatan yang terdiri dari pengkajian, perumusan diagnosa, perencanaan, pelaksanaan, dan evaluasi sebagai metode ilmiah penyelesaian masalah keperawatan pada pasien untuk meningkatkan outcome pasien (Aziz, 2002). Ciri dokumentasi asuhan keperawatan yang baik adalah berdasarkan fakta (factual basis), akurat (accuracy), lengkap (completeness), ringkas (conciseness), terorganisir (organization), waktu yang tepat (time liness), dan bersifat mudah dibaca (legability) (Potter \& 
Perry; 2009). Prinsipprinsip pendokumentasian direvisi menjadi tiga bentuk standar dokumentasi yaitu communication, accountability, dan safety (ANA, 2010).

Menurut Gibson dan Ivancevich terdapat tiga faktor yang mempengaruhi kinerja, yaitu faktor individu, faktor organisasi, dan faktor psikologi (Gibson, 2001). Faktor psikologi salah satunya motivasi, merupakan interaksi seseorang dengan situasi tertentu yang dihadapinya dan memberikan dorongan penggerak (disadari maupun tidak disadari) melalui suatu proses untuk mencapai tujuan tertentu yang Menurut Gibson dan Ivancevich terdapat tiga faktor yang mempengaruhi kinerja, yaitu faktor individu, faktor organisasi, dan faktor psikologi (Gibson, 2001). Faktor psikologi salah satunya motivasi, merupakan interaksi seseorang dengan situasi tertentu yang dihadapinya dan memberikan dorongan penggerak (disadari maupun tidak disadari) melalui suatu proses untuk mencapai tujuan tertentu yang diinginkan atau menjahui situasi yang tidak menyenangkan (Suarli \& Yayan, 2008). Faktor organisasi yaitu supervisi adalah pengamatan secara langsung dan berkala oleh atasan terhadap pekerjaan yang dilakukan bawahan, apabila ditemukan masalah segera diberikan bantuan yang bersifat langsung guna mengatasinya (Suarli \& Yayan, 2008).

Hal ini yang melatarbelakangi penulis untuk melakukan penelitian mengenai hubungan antara motivasi perawat dan supervisi dengan kualitas pendokumentasian proses keperawatan. Tujuan penelitian ini adalah untuk dapat mengetahui bahwa hubungan antara motivasi perawat dan supervise dengan kualitas dokumentasi proses keperawatan berhubangan erat yang dapat meningkatkan kualitas perawat dalam melakukan pendokumentasian dalam proses keperawatan.

\section{METODE}

Jurnal ini menggunakan metode analisis dari beberapa jurnal dengan memasukkan referensi kunci yang telah ditentukan. Adapun referensi dari jurnal yang saya gunakan merupakan jurnal yang diterbitkan pada 8 tahun terakhir ( dengan tahun paling tua 2012) yang mengarah pada tema Proses Keperawatan.Setelah itu membandingkan beberapa jurnal tersebut yang berhubungan dengan motivasi perawat, dan supervisi perawat dengan kualitas dokumentasi proses keperawatan.Dari analisi beberapa jurnal tersebut digunakan untuk mengetahui dan memahami hubungan bahwa motivasi perawat serta supervisi yang baik didalam diri seorang perawat akan berpengaruh dalam melakukan dokumentasi proses keperawatan. 


\section{HASIL}

Hasil pembandingan ini sesuai dengan penelitian Pakudek dkk (2013), Bara dan Suryati (2014), dan penelitian Agung (2009) yang membuktikan bahwa terdapat hubungan yang bermakna antara motivasi perawat dengan pelaksanaan dokumentasi keperawatan yang artinya berhubungan dengan pengkajian dalam proses keperawatan. Pelaksanaan proses pengkajian keperawatan, meliputi (1) faktor pendorong perawat melakukan proses pengkajian; (2) metode pengumpulan data dalam proses pengkajian; (3) manfaat melakukan pengkajian; dan (4) faktor penghambat pelaksanaan proses pengkajian.

Pelaksanaan pendokumentasian asuhan keperawatan harus dilakukan dengan baik dan benar. Namun, hasil analisis menunjukkan bahwa masih banyak perawat yang belum melaksanakan pendokumentasian asuhan keperawatan dengan baik dan benar. Banyak faktor yang mempengaruhi pelaksanaan pendokumentasian asuhan keperawatan, salah satunya adalah motivasi dari perawat itu sendiri.Motivasi seseorang dapat berasal dari dua sumber, yaitu motivasi yang berasal dari dalam diri dan motivasi yang berasal dari luar diri seseorang.

Pelaksanaan pendokumentasian asuhan keperawatan mempunyai manfaat sebagai cara komunikasi, pertanggung jawaban dan pertangung gugatan, pendidikan, penelitian, meningkatkan efektivitas dan efisiensi, sumber data, dan menjamin kualitas pelayanan. Oleh karena itu, pelaksanaan pendokumentasian harus sesuai dengan standar dokumentasi asuhan keperawatan yang telah di tetapkan. Nursalam (2008) menyebutkan instrument studi dokumentasi penerapan standar asuhan keperawatan di RS menggunakan instrument A dari Depkes (1995) meliputi: pengkajian keperawatan, diagnose keperawatan, perencanaan tindakan, implementasi keperawatan, evaluasi keperawatan dan catatan asuhan keperawatan.

Hasil dari pengkajian adalah supervisi merupakan hal yang sangat penting saat seseorang perawat akan mendokumentasikan asuhan keperawatan kepada pasiennya, karena masih ada beberpaa perawat yang jarang melengkapi dokumtasi asuhan keperawatan. Alasan mengapa perawat jarang untuk melengkapi dokumentasi asuhan keperawatan salah satu faktornya karena kurangnya pengawasan, pengontrolan terhadap dokumentasi asuhan keperawatan. Perawat merasa dokumentasi asuhan keperawatan terlalu banyak, tidak ada hubungannya dengan gaji serta kurangnya teguran dari atasan. Jumlah perawat ruangan yang sangat sedikit dengan 
kapasitas pasien dan beban kerja yang sangat banyak membuat perawat jarang menuliskan dokumentasi asuhan keperawatan secara lengkap, perawat biasanya hanya menuliskan nama pasien tanpa nomor RM, tidak melengkapi data pemeriksaan fisik pasien, tidak menuliskan analisa data, tujuan dan rencana tindakan, pada lembar implementasi perawat sering tidak menuliskan, evaluasi perawat sering tidak menuliskan catatan perkembangan pasien dan tidak mencantumkan paraf.

Pada hasil penelitian saya membandingkan beberapa jurnal ini dapat dijadikan acuan bahwa motivasi perawat dan supervisi itu penting didalam diri perawat untuk menumbuhkan rasa semangat dalam bekerja, sehingga jika dalam diri perawat semangat maka dokumentasi yang dilakukan pun akan tepat pula. Penyebab dari kurang baiknya dokumentasi asuhan keperawatan yang dilakukan adalah karena masih kurangnya pengetahuan dan pemahaman dari perawat, perawat lebih memprioritaskan tindakan langsung dari pada dokumentasi, serta kekurangan tenaga keperawatan.

\section{PEMBAHASAN}

Dokumentasi keperawatan menjadi instrumen penting untuk menjamin pelayanan kepada pasien karena digunakan sebagai panduan utama dalam upaya peningkatan pelayanan keperawatan. Dokumentasi yang tidak lengkap menyebabkan informasi menjadi tidak jelas dan membingungkan sehingga dapat menyebabkan kesalahan dalam penanganan pasien. Pendokumentasian merupakan bukti tertulis yang berguna untuk pertanggung jawaban perawat dalam melaksanakan asuhan keperawatan. Namun demikian banyak perawat tidak melakukan pendokumentasian karena merasa tugas itu menyita waktu sehingga banyak ditemukan ketidaklengkapan dalam dokumentasi keperawatan. Kepala ruangan bertanggung jawab dalam pendokumentasian asuhan keperawatan yang dilakukan oleh perawat pelaksana. Dokumentasi asuhan keperawatan mempunyai kegunaan dari berbagai aspek, seperti aspek hukum, jaminan mutu, komunikasi, keuangan, pendidikan, penelitian dan akreditasi.

Ciri dokumentasi asuhan keperawatan yang baik adalah berdasarkan fakta (factual basis), akurat (accuracy), lengkap (completeness), ringkas (conciseness), terorganisir (organization), waktu yang tepat (time liness), dan bersifat mudah dibaca (legability). Keakuratan suatu dokumentasi adalah salah bukti yang terbaik terhadap tuntutan yang berhubungan dengan asuhan 
keperawatan. Catatan dokumentasi berperan sebagai bukti otentik tertulis terhadap segala hal yang terjadi dan apa yang dilakukan perawat kepada pasien. Asuhan keperawatan bisa saja berjalan dengan sangat baik, namun apabila asuhan keperawatan yang baik tersebut tidak didokumetasikan, maka asuhan dianggap tidak dilakukan dalam peradilan hukum.

Terdapat tiga faktor yang mempengaruhi kinerja, yaitu faktor individu, faktor organisasi, dan faktor psikologi. Faktor psikologi salah satunya motivasi, merupakan interaksi seseorang dengan situasi tertentu yang dihadapinya dan memberikan dorongan penggerak (disadari maupun tidak disadari) melalui suatu proses untuk mencapai tujuan tertentu yang diinginkan atau menjauhi situasi yang tidak menyenangkan. Faktor organisasi, supervisi adalah pengamatan secara langsung dan berkala oleh atasan terhadap pekerjaan yang dilakukan bawahan, apabila ditemukan masalah segera diberikan bantuan yang bersifat langsung guna mengatasinya.

Motivasi merupakan kondisi yang berpengaruh membangkitkan, mengarahkan, dan memelihara perilaku yang berhubungan dengan lingkungan kerja. Motivasi yang tidak baik dalam pendokumentasian keperawatan akan membuat timbulnya dorongan yang lemah untuk melakukan pekerjaan sebaik mungkin. Motivasi kerja yang semakin tinggi menjadikan perawat mempunyai semangat yang tinggi untuk memberikan pelayanan yang terbaik.Hal ini sebanding dengan motivasi untuk melakukan pendokumentasian yang tinggi akan menghasilkan kualitas dokumentasi yang baik. Motivasi merupakan dorongan yang berpengaruh membangkitkan, mengarahkan, dan memelihara perilaku yang berhubungan dengan lingkungan kerja.

\section{Hubungan Supervisi dengan Kelengkapan Dokumentasi Keperawatan :}

Hasil penelitian mengidentifikasi sebagian besar perawat menilai kepala ruang telah melakukan supervisi dengan baik. Hasil ini sesuai dengan penelitian oleh Etlidawati (2012) yang juga mendapatkan hasil serupa. Perawat IGD RSUP Dr Kariadi menilai supervisi telah dilakukan dengan baik karena kepala ruang telah memberi pengarahan dan bimbingan kepada perawat. Hal ini tergambar dari pernyataan perawat bahwa kepala ruang memberikan penjelasan pentingnya dokumentasi keperawatan, memberikan dorongan, petunjuk, semangat, dan melakukan evaluasi terhadap kelengkapan dokumentasi keperawatan. Upaya yang dilakukan untuk memperbaiki kualitas dokumentasi dapat dilakukan dengan adanya dukungan yang berkelanjutan dari pimpinan. 
Supervisi kepala ruang merupakan bentuk dukungan yang diperlukan perawat agar kinerja dalam melaksanakan dokumentasi keperawatan dapat berjalan seperti yang diharapkan. Kepala ruang melaksanakan supervisi dengan membimbing, mengarahkan, melakukan observasi, memotivasi, serta mengevaluasi pelaksanaan asuhan keperawatan yang ditugaskan kepada perawat. Supervisi yang dilakukan dengan baik akan meningkatkan kualitas dokumentasi asuhan keperawatan.

\section{Hubungan beban kerja dengan keakuratan dokumentasi keperawatan :}

Hasil penelitian menunjukkan bahwa beban kerja obyektif perawat tidak memilki hubungan dengan keakuratan dokumentasi keperawatan. Setengah dari perawat dengan tindakan non produktif melakukan pendokumentasian keperawatan dengan cukup akurat.

Dokumentasi proses asuhan keperawatan yang baik dan berkualitas haruslah akurat, lengkap dan sesuai standar. Apabila kegiatan keperawatan tidak didokumentasikan dengan akurat dan lengkap maka sulit untuk membuktikan bahwa tindakan keperawatan telah dilakukan dengan benar. Faktor-faktor yang mempengaruhi keakuratan dokumentasi antara lain kurangnya pelatihan, belum optimalnya pengawasan, kurangnya motivasi, kurangnya pengetahuan dan kompetensi perawat, beban kerja yang tinggi, keterbatasan waktu, dan tidak adanya sistem pemberian reward dan punishment yang jelas serta sikap pimpinan yang kurang tegas dalam hal pelaksanaan pencatatan asuhan keperawatan.

Keakuratan dokumentasi keperawatan tidak berhubungan dengan beban kerja objektif perawat karena perawat tidak segera menulis atau mencatat hasil tindakan asuhan keperawatan di lembar dokumentasi keperawatan, sehingga pendokumentasian yang telah dilakukan perawat tidak dapat dijadikan sebagai bukti tindakan perawat. Pendokumentasian yang kurang akurat dapat menyebabkan terjadinya kesalahan komunikasi antar perawat maupun tim medis lain. Rumah sakit diharapkan melakukan pelatihan, bimbingan, dan motivasi agar beban kerja perawat ideal sehingga pelayanan asuhan keperawatan diberikan menjadi lebih berkualitas.

\section{Pengaruh Supervisi Terhadap Kelengkapan Dokumentasi Asuhan Keperawatan :}


Menurut teori supervisi terhadap pendokumentasian asuhan keperawatan merupakan kegiatan yang perlu dilakukan terhadap perawat pelaksana. Perawat perlu dijaga, dibina, dan ditingkatkan sikap positifnya terhadap pekerjaannya. Sikap positif perawat terhadap pekerjaannya akan tercapai apabila diberikan motivasi, bimbingan dan penghargaan terhadap hasil kerjanya yang akan menciptakan kepuasan kerja perawat. Kepuasan kerja perawat pada praktik keperawatan tercapai apabila perawat merasa telah memberikan kontribusi, dianggap penting, mendapat dukungan dari sumber-sumber yang ada, dan out-come keperawatan banyak tercapai.

Pelatihan merupakan faktor penting dalam meningkatkan kualitas kerja seseorang sesuai dengan tanggung jawabnya ditempat kerja. Pentingnya pelatihan pendokumentasian bagi perawat memberikan dampak positif terhadap kinerja perawat khususnya dalam melakukan pendokumentasian asuhan keperawatan. Dampak positif pelatihan yang sudah tergambar pada hasil penelitian ini harus menjadi bahan pertimbangan manajemen rumah sakit dalam melakukan pelatihan secara periodik untuk memberikan kesempatan bagi perawat yang belum mendapatkan pelatihan untuk lebih meningkatkan pendokumentasian.

\section{PENUTUP}

Dari hasil pembandingan beberapa jurnal motivasi perawat mempunyai hubungan yang erat dengan pelaksanaan pendokumentasian asuhan keperawatan sama dengan pelaksanaan pengkajian dalam proses keperawatan. Pelaksanaan proses pengkajian keperawatan merupakan kegiatan komperhensif perawat yang membutuhkan motivasi dan supervisi. Motivasi perawat yang cenderung kualitas dokumentasi baik dan Supervisi mempunyai hubungan yang signifikan dalam meningkatkan kualitas dokumentasi asuhan keperawatan. Bagi profesi keperawatan diharapkan hasil penelitian ini dapat dilaksanakan kepada seluruh perawat sehingga menjadi bahan pertimbangan untuk menerapkan di ruang rawat inap sehingga dapat meningkatkan kualitas pelayanan kepada pasien dan pendokumentasian asuhan keperawatan. Saran bagi rumah sakit, diharapkan selalu memperhatikan motivasi perawat dalam melakukan pendokumentasian asuhan keperawatan dalam proses keperawatan, sehingga diperlukan pembinaan misalnya dengan memberikan reward, peningkatan pendidikan, pelatihan, maupun seminar yang berkaitan dengan dokumentasi asuhan keperawatan.

\section{DAFTAR PUSTAKA}


1. Kusnadi,(2017). Analisis Kelengkapan Dokumentasi Keperawatan di Ruang Rawat Inap Non Intensive Rumah Sakit X . Jurnal Bidang Ilmu Kesehatan Vol. 9, No. 1

2. Fitrianola, Rezkiki dan Annisa Ilfa. (2018). Pengaruh Supervisi Terhadap Kelengkapan Dokumentasi Asuhan Keperawatan Di Ruangan Non Bedah. REAL in Nursing Journal (RNJ). Vol 1(2).

3. Ginting, Magdalena dan Junita Romaito Sinaga. (2019). HUBUNGAN PELAKSANA SUPERVISI KEPALA RUANG DENGAN PENDOKUMENTASIAN ASUHAN KEPERAWATAN DI RUMAH SAKIT MARTHA FRISKA PULO BRAYAN. JURNAL DARMA AGUNG HUSADA, Vol 5(1).

4. Harmain, L.M Siswanto, Rr Tutik Sri Hariyati dan Sukihananto. (2013). FAKTORFAKTOR YANG BERHUBUNGAN DENGAN KELENGKAPAN PENDOKUMENTASIAN ASUHAN KEPERAWATAN. Jurnal Keperawatan Indonesia. Vol 16 (2).

5. Kasim.M,Abdurrouf.M.(2016). PENINGKATAN KUALITAS PELAYANAN DAN PENDOKUMENTASIAN ASUHAN KEPERAWATAN DENGAN METODE TIM. NurseLine Journal Vol. 1 No. 1

6. Ida Yanti.R, Edi Warsito.B .(2013). HUBUNGAN KARAKTERISTIK PERAWAT, MOTIVASI, DAN SUPERVISI DENGAN KUALITAS DOKUMENTASI PROSES ASUHAN KEPERAWATAN .Jurnal Managemen Keperawatan . Volume 1, No. 2

7. M, B., \& B, S. (2014). Hubungan Motivasi Perawat dengan Pelaksanaan Pendokumentasian Asuhan Keperawatan di Ruang Rawat Inap RSUD Pasar Rebo. Jurnal Health Quality Vol. 5 No.1

8. Sapuan, Sri Andarini dan Dewi Kartikawatiningsih. (2019). HUBUNGAN SIKAP DAN SUPERVISI DENGAN KELENGKAPAN DOKUMENTASI KEPERAWATAN DI IGD RSUP Dr KARIADI SEMARANG. Jurnal keperawatan Malang. Vol 4 (1).

9. Simamora, R. H. (2019). Development of Guidelines for Applying appropriate Patient Identification to Achieve Patient Safety Goal INC2019 12th International Nursing Conference. 2019.10455 - 455 (1 pages) UCI(KEPA) : I410-ECN-0101-2019-512-001224337

10. Simamora. R. H. (2008) The correlation of ward chief's giving direction and command and the performance of on-duty nurses at Jember dr. Subandi general hospital inpatient wards. jurnal Administrasi dan Kebijakan Kesehatan, (https://fkm.unair.ac.id/jurnal-administr)

11. Wirawan,.E.A, Novitasari.D \& Wijayanti.F (2013). Hubungan antara Supervisi Kepala Ruang dengan Pendokumentasian Asuhan Keperawatan di Rumah Sakit Umum Daerah Ambarawa. Jurnal Manajemen Keperawatan, Vol 1(1) 
12. Yanti, R. I., \& Warsito, B. E. (2014). Hubungan Karakteristik Perawat, Motivasi, dan Supervisi dengan Kualitas Dokumentasi Proses Asuhan Keperawatan. Jurnal Manajemen Keperawatan Volume 1, No 2 